\title{
N-doped Graphene Supported on Metal-iron Carbide as a Catalyst for the Oxygen Reduction Reaction: Density Functional Theory Study
}

\author{
Patniboon, Tipaporn; Hansen, Heine Anton
}

Published in:

ChemSusChem

Link to article, DOI:

$10.1002 /$ cssc. 201903035

Publication date:

2020

Document Version

Peer reviewed version

Link back to DTU Orbit

Citation (APA):

Patniboon, T., \& Hansen, H. A. (2020). N-doped Graphene Supported on Metal-iron Carbide as a Catalyst for the Oxygen Reduction Reaction: Density Functional Theory Study. ChemSusChem, 13(5), 996-1005.

https://doi.org/10.1002/cssc.201903035

\section{General rights}

Copyright and moral rights for the publications made accessible in the public portal are retained by the authors and/or other copyright owners and it is a condition of accessing publications that users recognise and abide by the legal requirements associated with these rights.

- Users may download and print one copy of any publication from the public portal for the purpose of private study or research.

- You may not further distribute the material or use it for any profit-making activity or commercial gain

- You may freely distribute the URL identifying the publication in the public portal 


\section{CHEMISTRY \& SUSTAINABILITY

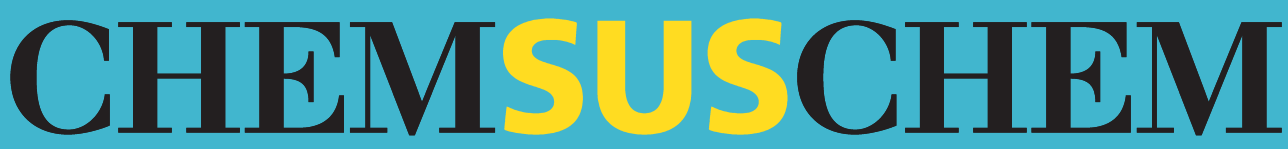

ENERGY \& MATERIALS

\section{Accepted Article}

Title: N-doped Graphene Supported on Metal-iron Carbide as a Catalyst for the Oxygen Reduction Reaction: Density Functional Theory Study

Authors: Tipaporn Patniboon and Heine Anton Hansen

This manuscript has been accepted after peer review and appears as an Accepted Article online prior to editing, proofing, and formal publication of the final Version of Record (VoR). This work is currently citable by using the Digital Object Identifier (DOI) given below. The VoR will be published online in Early View as soon as possible and may be different to this Accepted Article as a result of editing. Readers should obtain the VoR from the journal website shown below when it is published to ensure accuracy of information. The authors are responsible for the content of this Accepted Article.

To be cited as: ChemSusChem 10.1002/cssc.201903035

Link to VoR: http://dx.doi.org/10.1002/cssc.201903035 


\title{
N-doped Graphene Supported on Metal-iron Carbide as a Catalyst for the Oxygen Reduction Reaction: Density Functional Theory Study
}

\author{
Tipaporn Patniboon, and Heine Anton Hansen*[a]
}

\begin{abstract}
The development of efficient electrocatalyst for the oxygen reduction reaction (ORR) is essential for the commercialization of fuel cell technologies. Iron carbide encapsulated in $\mathrm{N}$-doped graphene ( $\mathrm{NG} / \mathrm{Fe}_{3} \mathrm{C}$ ) has been recently recognized as a promising ORR catalyst. In this study, the stability and catalytic activity of $\mathrm{N}$ doped graphene supported on metal-iron carbide (NG/M_Fe ${ }_{3} \mathrm{C}$ ) toward ORR are investigated using density functional theory (DFT) calculations. The NG/M_Fe ${ }_{3} \mathrm{C}$ heterostructure is modeled by substituting $\mathrm{Fe}$ atoms in the $\mathrm{Fe}_{3} \mathrm{C}$ substrate near the $\mathrm{NG} / \mathrm{Fe}_{3} \mathrm{C}$ interface by metal atoms $\mathrm{M}(\mathrm{M}=\mathrm{Cr}-\mathrm{Mn}$, Co $-\mathrm{Zn}, \mathrm{Nb}-\mathrm{Mo}, \mathrm{Ta}-\mathrm{W})$. The calculations show that the introduction of the metal atoms $\mathrm{M}$ alters the work function of the overlayer $\mathrm{N}$ doped graphene, which is found to correlate with the binding strength of the ORR intermediates. We find that introducing $\mathrm{Ni}$ or $\mathrm{Co}$ atoms at the interface improves the ORR activity of the $\mathrm{NG} / \mathrm{Fe}_{3} \mathrm{C}$ as well as stabilize the heterostructure. The ORR activity increases as the concentration of $\mathrm{Ni}$ or $\mathrm{Co}$ atoms near the interface increases, and the stable heterostructure is available in a wide range of substituted concentrations. These results suggest approaches to improve the ORR activity of $\mathrm{NG} / \mathrm{Fe}_{3} \mathrm{C}$ catalysts.
\end{abstract}

\section{Introduction}

Due to the continuing increase of the global energy demand, the depletion of fossil fuel, and concerns about the environment, transformative technologies changing the way we produce and use energy are required. These technologies must be sustainable, cleanly operating, and practically viable in terms of efficiency and affordability. The proton exchange membrane fuel cell (PEMFC) is one of the possible technologies fulfilling the requirements, especially for transport applications, owing to its low emission, high efficiency, and energy density ${ }^{[1-3]}$. In the PEMFC, hydrogen is oxidized and releases electrons at the anode. The stable heterostructures then travel through an electrical circuit while the protons pass through the electrolyte membrane to the cathode where the oxygen reduction reaction (ORR) takes place. With the electrons taken from the electrode and protons from the electrolyte, the oxygen molecule is reduced to form water molecules

[a] T. Patniboon, Assoc. Prof. H.A. Hansen Department of Energy Conversion and Storage Technical University of Denmark Fysikvej, 2800 Kgs. Lyngby, Denmark E-mail: heih@dtu.dk at the cathode. Unfortunately, the commercialization of the PEM fuel cell is impeded by to the high cost related to materials and components, especially related to the catalyst $^{[4]}$. The problem is mainly attributed to the use of Pt-based catalysts to overcome the sluggish kinetics of the ORR at the cathode ${ }^{[5]}$. Pt has been used commonly as an efficient catalyst in the PEMFC, but due to its prohibitive cost and low availability, Pt cost becomes the main cost component of the PEMFC ${ }^{[4]}$. In addition, Ptbased catalysts are unstable in the acid environment of the PEMFC, resulting in the loss of performance during extended operation ${ }^{[6]}$.

As a result, there are many attempts searching for new ORR catalysts based on Earth-abundant elements such as heteroatom (N, B, P, and S) doped carbon materials $^{[7]}$ or non-precious metal such as metalnitrogen-carbon (M-N-C) catalysts with non-precious metal such as $\mathrm{Fe}$ and $\mathrm{Co}^{[8-9]}$. Fe-N-C catalysts have been synthesized and exhibit ORR activity to comparable Ptbased catalysts and the $\mathrm{FeN}_{4}$ structure embedded within the carbon basal plane has been proposed as the active site ${ }^{[10-11]}$. However, the stability of the catalyst under the working conditions in the PEMFC still needs improvement ${ }^{[12]}$. Additionally, the active site for the ORR remains controversial since the Fe particles dispersed on the graphitic sheets and encased within graphitic shells are also present in the synthesized catalysts ${ }^{[10]}$. Later, carbon-encapsulated Fe-nanoparticles catalyst containing both $\mathrm{FeN}_{4}$ and $\mathrm{Fe}$ species has been prepared by Varnell at $\mathrm{el}^{[13]}$. This study suggested that the Fe species protected by carbon are the active species for the ORR while $\mathrm{FeN}_{4}$ sites are not required for the ORR activity.

Recently, the use of non-precious metal encased in a carbon material as the ORR catalyst has gained intense attention not only because of its low-cost, comparable catalytic activity to the Pt-based catalyst but also because of its long-term durability in acid conditions ${ }^{[14-17]}$. In this kind of the catalyst, the outer graphitic layer protects the inner core against corrosion in the acid environment while the inner particles activate the graphitic carbon layer toward the $\mathrm{ORR}^{[18]}$. For instance, $\mathrm{Fe}$ nanoparticles encapsulated in carbon shells ${ }^{[14]}$, Fe containing compounds encased in $\mathrm{N}$-doped graphitic layers ${ }^{[21]}$, and uniform $\mathrm{Fe}_{3} \mathrm{C}$ nanoparticles encased by graphitic layers have been successfully synthesized and demonstrated to possess high ORR activity and stability in acid ${ }^{[18]}$.

For the encapsulated Fe based catalyst, the role of the $\mathrm{Fe}$ and $\mathrm{Fe}_{3} \mathrm{C}$ phase in the catalyst activity has been questioned since the inner nanoparticles are a mixture of several phases i.e. $\mathrm{Fe}$ and $\mathrm{Fe}_{3} \mathrm{C}$ phase ${ }^{[21]}$. Lately, the role of $\mathrm{Fe}_{3} \mathrm{C}$ phase in activating the outer graphite layers 
toward ORR more efficiently than the Fe phase has been consistently confirmed by both experiments ${ }^{[22-23]}$ and a theoretical study ${ }^{[24]}$. Moreover, the $\mathrm{N}$-doing in the graphitic layer has been shown to enhance the ORR activity of the Fe based catalyst ${ }^{[13,21-24]}$.

Recently, many studies have explored the synthesis of bimetallic carbide encapsulated in $\mathrm{N}$-doped graphene and showed that it displayed a better ORR activity and stability than that of the $\mathrm{Fe}_{3} \mathrm{C}$ catalyst. For instance, the cobalt-iron carbide nanoparticles encapsulated by $\mathrm{N}$ doped graphene nanosheet (NG/CoFe carbide) has already been synthesized. Upon testing as the ORR catalyst, the NG/CoFe carbide exhibits higher ORR activity than those of $\mathrm{NG} / \mathrm{Fe}_{3} \mathrm{C}, \mathrm{NG} / \mathrm{CO}_{2} \mathrm{C}$, and $\mathrm{NG}{ }^{[25]}$. Additionally, Lin et al. have incorporated manganese $(\mathrm{Mn})$ into the $\mathrm{Fe}_{3} \mathrm{C}$ crystal structure and shown that the manganese-iron binary carbide nanoparticle armored by $\mathrm{N}$-doped graphene also has higher ORR activity than $\mathrm{NG} / \mathrm{Fe}_{3} \mathrm{C}^{[26]}$.

In this present work, density functional theory (DFT) calculations are used to study metal-iron carbide supporting $\mathrm{N}$-doped graphene aiming to identify new promising catalysts for the ORR and understand the fundamental nature of the ORR on these catalysts. We use the $\mathrm{NG} / \mathrm{Fe}_{3} \mathrm{C}$ heterostructure as a prototype. Since the electronic structure of 2D materials such as graphene sheet and $\mathrm{MoS}_{2}$ can be tuned by the coupling with the support materials ${ }^{[27]}$, the introduction of new metal atoms in the $\mathrm{Fe}_{3} \mathrm{C}$ substrate is expected to modify the electronic structure of the overlayer $\mathrm{N}$-doped graphene and alter the ORR catalytic activity of the $\mathrm{NG} / \mathrm{Fe}_{3} \mathrm{C}$ system. Promising ORR catalysts should show improved ORR catalytic activity over $\mathrm{NG} / \mathrm{Fe}_{3} \mathrm{C}$ and be as stable as possible.

\section{Computational methods}

All calculations in this study are performed using spin-polarized density functional theory (DFT) calculations as implemented in the Viena ab initio simulation package (VASP) ${ }^{[28-31]}$ coupled with the Atomic Simulation Environment (ASE) ${ }^{[32]}$. The core electrons are described by the projector augmented wave (PAW) ${ }^{[33-34]}$ method, and the wave function is expanded in the planewave basis set with an energy cutoff of $400 \mathrm{eV}$. Since the catalyst structures considered in this study are a graphene sheet stacked on a metal-iron carbide layer where a non-local van der Walls (vdW) interaction plays a significant role, the exchange and correlation are approximated by the BEFF-vdW functional ${ }^{[35]}$ in which vdW-DF2 ${ }^{[36]}$ non-local correlation is used. This functional has been proved to be successful in describing chemisorption as well as physisorption on a transition metal surface ${ }^{[35,37]}$. The dipole corrections are applied in the direction perpendicular to the catalyst surface to decouple electrostatic potentials on the two sides of the catalyst structure. The Fermi smearing of the electronic occupation with a width of $0.1 \mathrm{eV}$ and a Monkhorst-Pack mesh $^{[38]}$ for Brillouin zone sampling of $\left(k_{1}, k_{2}, k_{3}\right)$ with $k_{i}$ such that $k_{i} v_{i}>30$ for $v_{i}$ corresponding to a lattice vector. The structure relaxation is continued until the maximum force on each atom is below $0.02 \mathrm{eV} / \AA$. The thickness of the vacuum layer between periodic images is set to be 14 $\AA$ to avoid interaction between the periodic images.

\section{Results and Discussion}

Structure of the interface. The unit cell of the $\mathrm{NG} / \mathrm{Fe}_{3} \mathrm{C}$ heterostructure has been prepared by Reda et al. ${ }^{[24]}$ consisting of 7 atomic layers of $\mathrm{Fe}_{3} \mathrm{C}(010)$ slab (6.8 Angstrom) overlayered by $\mathrm{N}$-doped graphene with surface cell dimensions of $(6.52,0.00) \times(0.93,6.45) \AA$. It has been found that there is no graphitic carbon at the interface in the lowest energy structure of the $\mathrm{NG} / \mathrm{Fe}_{3} \mathrm{C}$ heterostructure ${ }^{[24]}$. The overlayer $\mathrm{N}$-doped graphene consists of 15 carbon atoms and one nitrogen dopant atom, corresponding to $6.25 \% \mathrm{~N}$ in the graphene sheet. In the following, $\mathrm{NG} / \mathrm{M}_{-} \mathrm{Fe}_{3} \mathrm{C}$ refers to the heterostructure with the metal atoms $\bar{M}$ introduced in the $\mathrm{Fe}_{3} \mathrm{C}$ substrate near the interface ( $w h e r e \mathrm{M}=\mathrm{Cr}-\mathrm{Mn}, \mathrm{Co}-\mathrm{Zn}, \mathrm{Nb}-\mathrm{Mo}$, $\mathrm{Ta}-\mathrm{W}$ ). The NG/M_Fe ${ }_{3} \mathrm{C}$ is modelled by substituting one layer of $\mathrm{Fe}$ atoms in the $\mathrm{Fe}_{3} \mathrm{C}$ substrate from the NG/Fe ${ }_{3} \mathrm{C}$ interface by metal atoms $M$. The interchange of introduced metal atoms between layers is taken into account, so the introduced metal atoms substitute $\mathrm{Fe}$ atoms either in the first $\left(\mathrm{NG} / \mathrm{M}_{-} 1^{\text {st }} \mathrm{Fe}_{3} \mathrm{C}\right)$ or the second layer (NG/M_2 $2^{\text {nd }}-\mathrm{Fe}_{3} \mathrm{C}$ ) of the $\mathrm{Fe}_{3} \mathrm{C}$ substrate from the interface as shown in Figure 1.
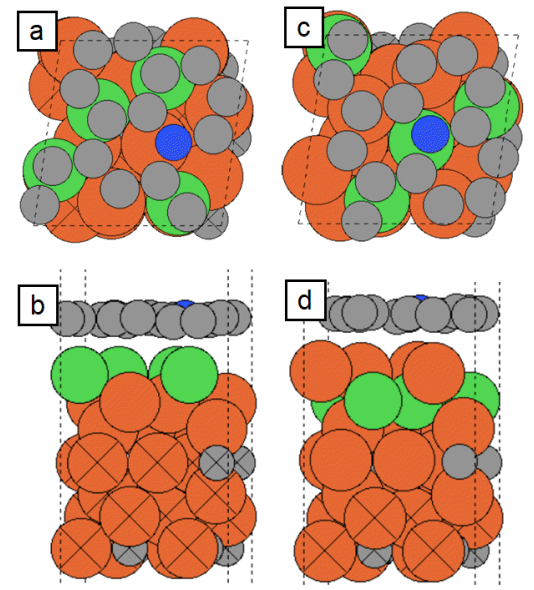

Figure 1. Interface models of $\mathrm{NG} / \mathrm{Ni}_{-} 1^{\text {st }} \mathrm{Fe}_{3} \mathrm{C}$ : (a) top view, (b) side view and $\mathrm{NG} / \mathrm{Ni} 2^{\text {nd }}{ }_{-} \mathrm{Fe}_{3} \mathrm{C}$ (c) top view, (d) side view. Cross marks indicate atoms that are fixed during the structure relaxation. Colors for atoms: C-gray, $\mathrm{N}$-blue, Ni-green, Fe-orange.

Except for $\mathrm{M}=\mathrm{Cu}$ or $\mathrm{Zn}$, the heterostructures with the introduced metal atoms $M$ at the interface have interlayer distances of $2.08-2.33 \AA$, suggesting an interfacial interaction between the $\mathrm{N}$-doped graphene and the substrate. As a result of the interfacial interaction, an average Bader charge transfer from the metal-iron carbide substrate to the $\mathrm{N}$-doped graphene of 0.029 0.073 electron/(NG atoms) is found. For the heterostructure with $\mathrm{Cu}$ or $\mathrm{Zn}$ at the interface, the graphene-carbide distance is found to be 3.35 and 3.60 $\AA$, respectively, suggesting a weak interaction between the $\mathrm{N}$-doped graphene and the substrate. The Bader charge analysis shows that there is no net Bader charge 
transfer from the substrate to the $\mathrm{N}$-doped graphene overlayer in these two latter heterostructures.

We first calculate the interface layer formation energy $\left(\Delta E_{\text {int }}\right)$, which we define as the energy used to form a single layer of the introduced metal atoms (and Fe atoms) on the $\mathrm{Fe}_{3} \mathrm{C}$ substrate at the interface from the bulk phase of the introduced metal atoms. It is defined by the equation

$\Delta E_{\text {int }}=\frac{1}{n}\left(E\left(\mathrm{NG} / \mathrm{M}_{-} 1^{\mathrm{st}}-\mathrm{Fe}_{3} \mathrm{C}\right)-E\left(\mathrm{NG} / 0{ }_{-} 1^{\mathrm{st}}-\mathrm{Fe}_{3} \mathrm{C}\right)-n E(\mathrm{M})\right)$

where $E\left(\mathrm{NG} / 01^{\text {st }} \mathrm{Fe}_{3} \mathrm{C}\right)$ is the total energy of the $\mathrm{NG} / \mathrm{Fe}_{3} \mathrm{C}$ heterostructure with $\mathrm{Fe}$ atoms at the first layer of the $\mathrm{Fe}_{3} \mathrm{C}$ are removed. $E\left(\mathrm{NG} / \mathrm{M}_{-} 1^{\text {st }} \mathrm{Fe}_{3} \mathrm{C}\right)$ is the total energy of the heterostructure with the metal atoms $M$ at the first layer of the $\mathrm{Fe}_{3} \mathrm{C}$ substrate. $E(M)$ is the total energy per atom of metal $\mathrm{M}$ in the bulk structure, and $n$ is the number of $\mathrm{Fe}$ atoms in the first layer of the $\mathrm{Fe}_{3} \mathrm{C}$ substrate. Negative values of $\Delta E_{\text {int }}$ indicate that it is energetically favorable to form a single layer of the introduced metal on the $\mathrm{Fe}_{3} \mathrm{C}$ substrate from the bulk metal phase.

The interchange of metal atoms between layers is investigated here by considering the exchange of the introduced metal atoms from the first layer to the second layer of the $\mathrm{Fe}_{3} \mathrm{C}$ substrate. In this way, the exchange energy of the introduced metal atoms $\left(\Delta E_{e x c}\right)$ is defined by the equation

$\Delta E_{e x c}=\frac{1}{n}\left(E\left(N G / M \_2^{n d}-F e_{3} C\right)-E\left(N G / M \_1^{s t}-F e_{3} C\right)\right)$

where $E\left(\mathrm{NG} / \mathrm{M}_{-} 1^{\text {st }} \mathrm{Fe}_{3} \mathrm{C}\right)$ and $E\left(\mathrm{NG} / \mathrm{M} 2^{2}{ }^{\text {nd }}{ }_{-} \mathrm{Fe}_{3} \mathrm{C}\right)$ is the total energy of the heterostructure with the introduced metal atoms $M$ in the first and second layer of the $\mathrm{Fe}_{3} \mathrm{C}$ substrate, respectively. Negative values of $\Delta E_{\text {exc }}$ indicate that the introduced metal atoms preferably sits within the $\mathrm{Fe}_{3} \mathrm{C}$ substrate.

The stability of the heterostructure is investigated by calculating the formation energy of the heterostructure relative to both the pure metal phase and the metal carbide phase of the introduced metal element. The formation energy of the heterostructure relative to the pure metal phase $\left(\Delta E_{f}(M)\right)$ is defined by the following equation.

$$
\Delta E_{f}(\mathrm{M})=E\left(\mathrm{NG} / \mathrm{M} \_\mathrm{Fe}_{3} \mathrm{C}\right)+n E(\mathrm{Fe})-E\left(\mathrm{NG} / \mathrm{Fe}_{3} \mathrm{C}\right)-n E(\mathrm{M})
$$

where $E\left(\mathrm{NG} / \mathrm{M}_{-} \mathrm{Fe}_{3} \mathrm{C}\right)$ is the total energy of the heterostructure with the introduced metal atoms $M$ either in the first or second layer from the interface, $E\left(\mathrm{NG} / \mathrm{Fe}_{3} \mathrm{C}\right)$ is the total energy of the pristine $\mathrm{NG} / \mathrm{Fe}_{3} \mathrm{C}$ heterostructure. $E(\mathrm{Fe})$ is total energy per Fe atom and $n$ is the number of $\mathrm{Fe}$ atoms in the $\mathrm{Fe}_{3} \mathrm{C}$ substrate that are substituted by the introduced metal atoms.

The formation energy relative to the metal carbide phase of the metal atom $M$ is considered here because some metal elements favor forming a metal carbide phase rather than their pure metal phase in the presence of carbon. In this way, in the presence of graphite, the introduced metal atom possibly leaves the heterostructure and forms a separate metal carbide phase (see Table S1, Supporting Information). The mixing between metal and the carbon atoms is expected during the synthesis using pyrolysis ${ }^{[20]}$ or a carbon arc discharge reactor ${ }^{[39-40]}$. The formation energy of the heterostructure relative to the metal carbide phase $\left(\Delta E_{f}(M C)\right)$ is calculated from the following equation.

$\Delta E_{f}(\mathrm{MC})=E\left(\mathrm{NG} / \mathrm{M} \_\mathrm{Fe}_{3} \mathrm{C}\right)+\frac{n y}{x} E(\mathrm{C})+n E(\mathrm{Fe})-E\left(\mathrm{NG} / \mathrm{Fe}_{3} \mathrm{C}\right)-\frac{n}{x} E\left(\mathrm{M}_{\mathrm{x}} \mathrm{C}_{\mathrm{y}}\right)$

where $E\left(M_{x} C_{y}\right)$ is total energy per formula of a stable metal carbide phase $\left(M_{x} C_{y}\right)$ of the introduced metal $M$ in which $x$ and $y$ are the stoichiometry of element $M$ and $C$ in the $M_{x} C_{y}$ formula. $E(C)$ is the total energy per atom of carbon in graphite. The formation energy of the heterostructure relative to the metal carbide phase considers only the metal carbide phase of the introduced metal $\mathrm{M}$ because the formation energy of $\mathrm{Fe}_{3} \mathrm{C}$ based on the calculations in this study is the most positive among the considered metal elements. Therefore $M_{x} C_{y}$ is more likely to form than $\mathrm{Fe}_{3} \mathrm{C}$ when $\mathrm{Fe}, \mathrm{M}$, and $\mathrm{C}$ mix (Table S1, Supporting Information). The formation energies relative to the metal carbide phase of the heterostructure with $\mathrm{Cu}$ and $\mathrm{Zn}$ are not considered here since these two elements do not directly react with carbon ${ }^{[40]}$.

The calculations show that most of the considered heterostructures, except the heterostructures with $\mathrm{Co}, \mathrm{Ni}$, $\mathrm{Cu}$, and $\mathrm{Zn}$ are unstable against phase separation to form the separate metal carbide phase. The heterostructures with $\mathrm{Cr}, \mathrm{Mn}, \mathrm{Mo}$, and $\mathrm{W}$ are not even stable against phase separation to form the pure metal phase. We find that $\Delta E_{\text {int }}$ of $\mathrm{Cr}, \mathrm{Mn}, \mathrm{Mo}$, and $\mathrm{W}$ are more positive than that of $\mathrm{Fe}$, implying that forming the single layer of these metal at the interface is more difficult than for Fe atoms. The negative value of $\Delta E_{\text {exc }}$ confirms the instability of these metal atoms at the interface (Table S2, Supporting Information).

The heterostructures with $\mathrm{Co}$ and $\mathrm{Ni}$ atoms are stable relative to both the pure metal and the metal carbide phase. This could be explained by the unfavorability to form the metal carbide phase and the favourability to form the single layer on the $\mathrm{Fe}_{3} \mathrm{C}$ substrate (negative value of $\Delta E_{\text {int }}$ ). However, as the formation energies relative to the metal carbide phase are more negative than those related to the pure metal phase, the heterostructures with $\mathrm{Ni}$ and $\mathrm{Co}$ atoms are more stable against the phase separation to form the metal carbide phase than the pure metal phase. The formation energy difference of the heterostructure with $\mathrm{Ni}$ or Co atoms in the first and second layer from the interface is found to be less than $0.02 \mathrm{eV}$, suggesting that $\mathrm{Ni}$ and $\mathrm{Co}$ atoms can distribute between the first and second layer of the $\mathrm{Fe}_{3} \mathrm{C}$ substrate.

Stable heterostructures are likely to form with $\mathrm{Cu}$ or $\mathrm{Zn}$ atoms at the interface, unlike the $\mathrm{Ni}$ and $\mathrm{Co}$ substitution. This can be related to the segregation which is closely related to the surface energy ${ }^{[41-42]}$ and atomic radius $^{[42]}$. According to our calculations, $\Delta E_{\text {int }}$ of $\mathrm{Co}, \mathrm{Ni}$, $\mathrm{Cu}$, and $\mathrm{Zn}$ are more negative than $\mathrm{Fe}$, implying it is energetically favorable for these metal atoms to form a single layer on the $\mathrm{Fe}_{3} \mathrm{C}$ surface (Table S2, Supporting Information). The atomic size difference between the 
substituted metal atom and the Fe atom can influence the segregation ${ }^{[42,44]}$. When the substituted metal atoms are in the second layer of the $\mathrm{Fe}_{3} \mathrm{C}$ substrate, the atomic size difference between the substituted metal and $\mathrm{Fe}$ increases strain in the bulk structure, and to relieve the strain, the introduced metal atoms in the bulk exchange with $\mathrm{Fe}$ atoms at the surface ${ }^{[42-44]}$. The atomic size difference between the substituted metal atom and $\mathrm{Fe}$ atom in the case of $\mathrm{Cu}$ and $\mathrm{Zn}$ is relatively larger than those of $\mathrm{Ni}$ and $\mathrm{Co}$ (atomic radius $=1.26,1.25,1.25$, 1.29 , and $1.38 \AA$ for $\mathrm{Fe}, \mathrm{Co}, \mathrm{Ni}, \mathrm{Cu}$, and $\mathrm{Zn}$ respectively ${ }^{[45]}$, leading to larger strain and driving force for $\mathrm{Cu}$ and $\mathrm{Zn}$ atoms to segregate toward the $\mathrm{Fe}_{3} \mathrm{C}$ surface, compared to $\mathrm{Ni}$ and $\mathrm{Co}$ atoms. In the calculations, we also find that $\mathrm{Cu}$ and $\mathrm{Zn}$ have a more positive value of $\Delta E_{\text {exc }}$ than those of $\mathrm{Ni}$ and $\mathrm{Co}$, thus describing the easier surface segregation of $\mathrm{Cu}$ and $\mathrm{Zn}$ toward the $\mathrm{Fe}_{3} \mathrm{C}$ surface than $\mathrm{Ni}$ and $\mathrm{Co}$ atoms.

ORR activity. Based on the computational hydrogen electrode (CHE) model as proposed by Nørskov et al. ${ }^{[46] \text {, }}$ the stability of the surface intermediate relates to the free energy of the reaction and can be established as a function of applied electrode potential. In this study, we focus on the associative mechanism of the ORR process since there are previous studies indicating that on the $\mathrm{N}$ doped graphene, the associative mechanism is more energetically favorable than the dissociative mechanism ${ }^{[47]}$. The $\mathrm{O}_{2}$ dissociation barrier at the active site on the $\mathrm{N}$-doped graphene has been reported to be $1.20 \mathrm{eV}$, which is unlikely to occur at room temperature ${ }^{[48]}$. The four-electron elementary reaction step along the four-electron associative mechanism can be written as:

$$
\begin{aligned}
& *+\mathrm{O}_{2}+\mathrm{H}^{+}+\mathrm{e}^{-} \rightarrow * \mathrm{OOH} \\
& * \mathrm{OOH}+\mathrm{H}^{+}+\mathrm{e}^{-} \rightarrow * \mathrm{O}+\mathrm{H}_{2} \mathrm{O} \\
& * \mathrm{O}+\mathrm{H}^{+}+\mathrm{e}^{-} \rightarrow * \mathrm{OH} \\
& * \mathrm{OH}+\mathrm{H}^{+}+\mathrm{e}^{-} \rightarrow *+\mathrm{H}_{2} \mathrm{O}
\end{aligned}
$$

where $*$ denote an active site on the catalyst surface. In this study, the carbon next to $\mathrm{N}$ dopant atom is considered as an active site ${ }^{[49]}$. The adsorption free energy of $* \mathrm{OOH}, * \mathrm{O}$ and $* \mathrm{OH}$ are defined relative to $\mathrm{H}_{2} \mathrm{O}$ and $\mathrm{H}_{2}$ by the following equations.

$$
\begin{array}{ll}
*+2 \mathrm{H}_{2} \mathrm{O} \longrightarrow{ }^{*} \mathrm{OOH}+\frac{3}{2} \mathrm{H}_{2}, & \Delta \mathrm{G}(* \mathrm{OOH}) \\
*+\mathrm{H}_{2} \mathrm{O} \longrightarrow{ }^{*} \mathrm{O}+\mathrm{H}_{2}, & \Delta \mathrm{G}(* \mathrm{O}) \\
*+\mathrm{H}_{2} \mathrm{O} \longrightarrow{ }^{*} \mathrm{OH}+\frac{1}{2} \mathrm{H}_{2}, & \Delta \mathrm{G}(* \mathrm{OH})
\end{array}
$$

The Gibbs free energies of the adsorbates are calculated assuming the adsorbate vibrational degrees of freedom are independent quantum mechanical harmonic oscillators and can calculated from the following equation. where $\Delta E(X)$ is the reaction DFT energy forming the adsorbate $\mathrm{X}$ (where $\mathrm{X}={ }^{*} \mathrm{OOH}, * \mathrm{O}$ and $* \mathrm{OH}$ ) binding to the catalyst surface. $\Delta E_{Z P E}$ and $T \Delta S$ is zero-point energy change and entropy change upon adsorbate formation. The vibrational contributions to the Gibbs free energy calculated on unsupported N-doped graphene were used to approximate all catalyst structures because the vibration contributions on the unsupported $\mathrm{N}$-doped graphene, $\mathrm{NG} / \mathrm{Fe}_{3} \mathrm{C}$, and $\mathrm{NG} / \mathrm{Ni}_{2} 1^{\text {st }} \mathrm{Fe}_{3} \mathrm{C}$ are identical within $0.01 \mathrm{eV}$ for each adsorbate. In this way, $\Delta E_{Z P E}+$ $T \Delta S$ is approximated to be $0.45,0.07$, and $0.39 \mathrm{eV}$ for $* \mathrm{OOH}, * \mathrm{O}$, and $* \mathrm{OH}$ adsorbate, respectively. The Gibbs free energies of gas-phase molecules are calculated from the experimental entropies and vibrational frequencies [50-51]. The total energy of the catalyst with the adsorbates are corrected according to the Christensen's correction scheme: $\Delta E(\mathrm{O}-\mathrm{O})=0.2 \mathrm{eV}, \Delta E\left(\mathrm{H}_{2} \mathrm{O}\right)=-0.03 \mathrm{eV}$ and $\Delta E\left(\mathrm{H}_{2}\right)=0.09 \mathrm{eV}^{[52-53]}$.

By setting the reversible hydrogen electrode (RHE) as the reference electrode, the applied electrode potential $\left(U V_{R H E}\right)$ alter each consecutive state along the ORR pathway by -neU where $n$ is the number of a transferred electron-proton pairs in each consecutive state, and $e$ is the elementary positive charge. In this way, the Gibbs free energy of the four elementary reaction steps according to Equation (5) - (8) at $U=0 \mathrm{~V}_{\mathrm{RHE}}$ can be written as the following equations.

$$
\begin{aligned}
\Delta G_{1} & =\Delta G(* \mathrm{OOH})-\Delta G_{O R R} \\
\Delta G_{2} & =\Delta G(* \mathrm{O})-\Delta G(* \mathrm{OOH}) \\
\Delta G_{3} & =\Delta G(* \mathrm{OH})-\Delta G(* \mathrm{O}) \\
\Delta G_{4} & =-\Delta G(* \mathrm{OH})
\end{aligned}
$$

where $\triangle$ GORR is the overall formation free energy of the ORR $\left(2 \mathrm{H}_{2}+\mathrm{O}_{2} \rightarrow \mathrm{H}_{2} \mathrm{O}\right)$ which is fixed at the experimental value at $T=25^{\circ} \mathrm{C}, p\left(\mathrm{H}_{2}\right)=p\left(\mathrm{O}_{2}\right)=1 \mathrm{bar}\left(\Delta G_{O R R}=-4.92\right.$ $\mathrm{eV}$ ) to avoid calculation of the $\mathrm{O}_{2}$ energy, which is poorly described by $\mathrm{DFT}^{[54]}$. At this value, the thermodynamic equilibrium potential will be $1.23 \mathrm{~V}_{\mathrm{RHE}}$. The activity of an ORR catalyst is evaluated by the theoretical overpotential ( implies a better ORR activity.

$\eta_{O R R}=1.23-\max \left\{\Delta G_{1}, \Delta G_{2}, \Delta G_{3}, \Delta G_{4}\right\} / e$
$\Delta G(\mathrm{X})=\Delta E(\mathrm{X})+\Delta \mathrm{E}_{\mathrm{ZPE}}-T \Delta S$ 

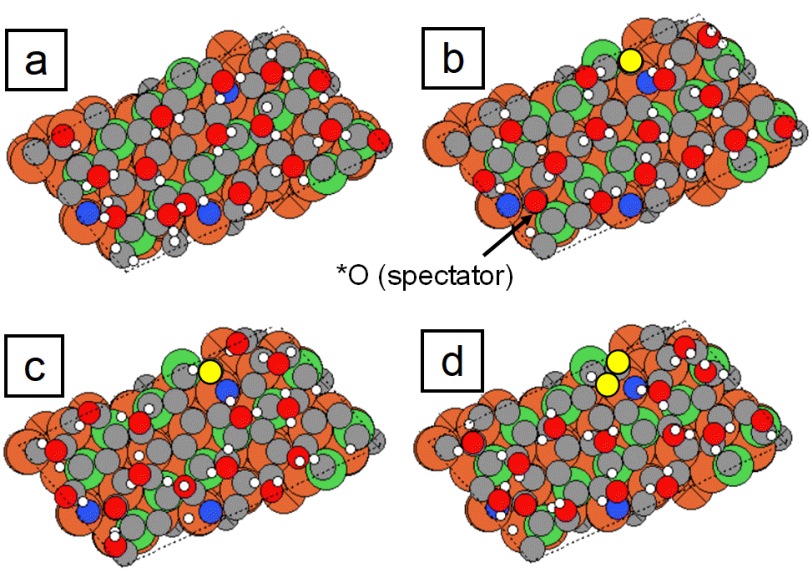

Figure 2. Interface models of $\mathrm{NG} / \mathrm{Ni}_{1} 1^{\text {st }} \_\mathrm{Fe}_{3} \mathrm{C}$ (a triplet $\sqrt{ } 2 \times \sqrt{ } 3$ cell) with an explicit water layer (top view): (a) without adsorbate, (b) two *O, (c) *O and $* \mathrm{OH}$, (d) *O and $* \mathrm{OOH}$. Colors for atoms: C-gray, N-blue, Ni-green, Fe-orange, O-red, $\mathrm{H}$-white. Oxygen atoms belonging to adsorbates at the active site are highlighted in yellow.

The study by Reda et al. reported that the presence of nearby unoccupied nitrogen atom where its neighboring carbon atoms and the nitrogen atom itself do not bond with any adsorbates, significantly stabilizes the adsorption of $* \mathrm{O}$ intermediates on $\mathrm{N}$-doped graphene ${ }^{[55]}$. The lack of free nitrogen atoms in the catalyst model could lead to artificially weak *O binding, while too many free nitrogen atoms could cause the reduction reaction of $* \mathrm{O}$ to $* \mathrm{OH}$ becomes the potential-determining step ${ }^{[55]}$. To take advantage of the free nitrogen effect and minimize the barrier along the ORR free energy diagram, the free nitrogen atoms and $* O$ adsorbate (as spectator which will be present on the catalyst surface throughout the entire oxygen reduction process) are recommended to include into the catalyst model with the optimal adsorbate coverage in the range of $1 / 2<\theta_{\text {ads }}<1^{[55]}$. Consequently, the $\mathrm{NG} / \mathrm{Fe}_{3} \mathrm{C}$ unit cell is extended in the surface plane to obtain a triplet $(\sqrt{ } 2 \times \sqrt{ } 3)$ cell as shown in Figure 2 . The catalyst model then contains three nitrogen atoms in the unit cell. An oxygen atom serving as a spectator occupies the first nitrogen atom. The other two nitrogen atoms serve as the free nitrogen and the active site.

Water solvation is taken into account in the ORR model since the catalyst is supposed to work in an aqueous environment of the PEMFC where the interaction between a surrounding water molecule and the ORR intermediates via a hydrogen bond can affect the stability of ORR adsorbates ${ }^{[47,55-57]}$. Hence, including explicit $\mathrm{H}_{2} \mathrm{O}$ molecules is recommended to be essential for accurate description of the ORR intermediates ${ }^{[55]}$. In the pristine structure, a single water layer consisting of 16 water molecules $\mathrm{Ni}$ and $\mathrm{Co}$ atoms, respectively substitute only half of $\mathrm{Fe}$ atoms in the layer on top of the $\mathrm{N}$-doped graphene surface (Figure 2(a)).

The optimized structures of the single water layer have been prepared by Reda et al. ${ }^{[24]}$ using the minima hopping algorithm implement in $\mathrm{ASE}^{[58-59]}$ and the number of water molecules has been found to be sufficient to reproduce the solvation effect on the $\mathrm{N}$ doped graphene as well as the $\mathrm{NG} / \mathrm{Fe}_{3} \mathrm{C}^{[24,55]}$.

The adsorption energies of the ORR intermediates in the presence of explicit water are calculated by replacing one $\mathrm{H}_{2} \mathrm{O}$ molecule from the water layer by an adsorbate, and the energy of that water molecule is assumed to be the average energy of $\mathrm{H}_{2} \mathrm{O}$ molecule in the water layer without adsorbate.

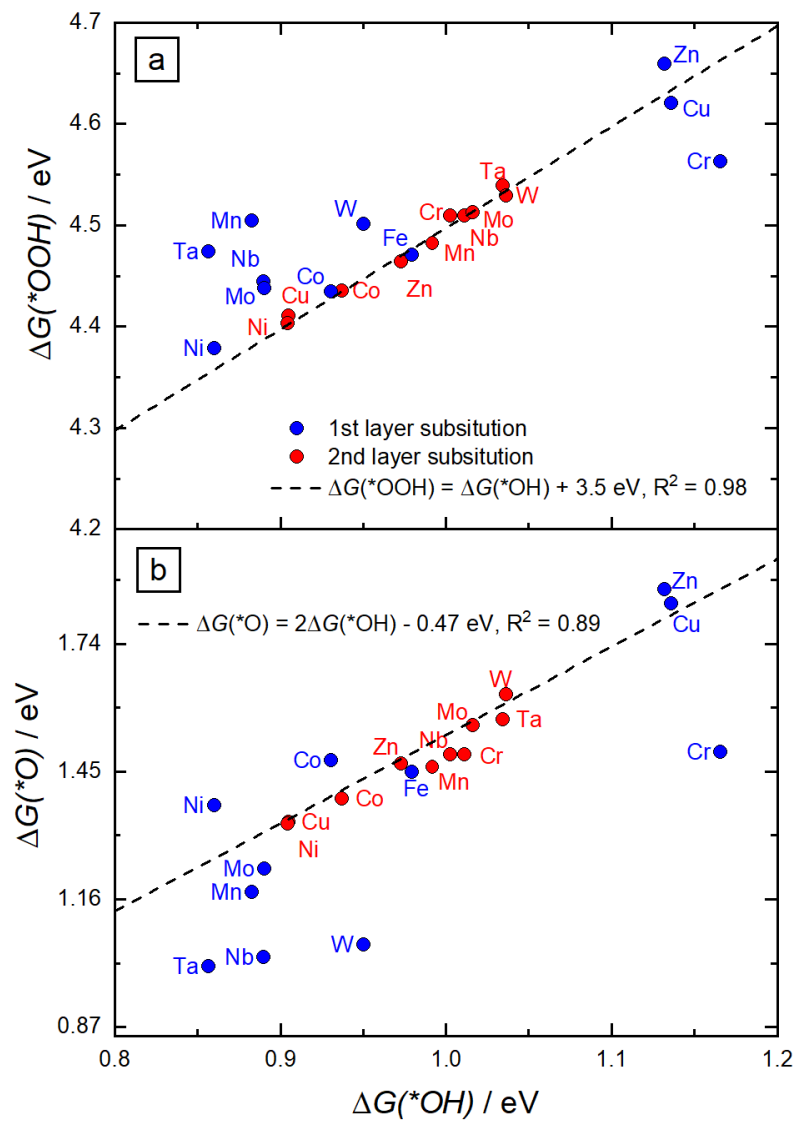

Figure 3. Scaling relation between the adsorption free energies of the adsorbates on the NG/M_Fe ${ }_{3} \mathrm{C}:(a) * O O H$ vs. ${ }^{*} \mathrm{OH}$, (b) $* \mathrm{O}$ vs. $* \mathrm{OH}$.

Figure 3 shows $\Delta G(* \mathrm{OOH})$ vs. $\Delta G(* \mathrm{OH})$ and $\Delta G\left({ }^{*} \mathrm{O}\right)$ vs. $\Delta G(* \mathrm{OH})$. The results show that the presence of the new metal element near the $\mathrm{NG} / \mathrm{Fe}_{3} \mathrm{C}$ interface can alter the adsorption free energies of ORR intermediate.

In addition, the results are quite scattered, especially for the first layer substitution with the substituted atoms having a larger atomic radius than $\mathrm{Fe}(\mathrm{Cr}, \mathrm{Mn}, \mathrm{Nb}, \mathrm{Mo}$, $\mathrm{Ta}$, and $\mathrm{W}$ ). In this case, the introduced metal atoms possibly move and rearrange during the structure relaxation since the introduced metal atom is larger than the Fe vacancy site, and there is space available at the interface. We find that the introduced metal atoms with a larger atomic radius than Fe moves about $1.7 \AA$ after the structure relaxation and forms a new atomic arrangement at the interface deviated from the initial $\mathrm{Fe}_{3} \mathrm{C}(110)$ configuration. This could create a distinct structural environment for the carbon atom in the overlayer $\mathrm{N}$ doped graphene in each heterostructure, resulting in the scattering of adsorption free energies for the ORR 
intermediates. Introducing fewer metal atoms in the first layer of the $\mathrm{Fe}_{3} \mathrm{C}$ substrate could mitigate interface reconstruction. On the other hand, the average movement of the introduced metal atoms with a smaller atomic radius than the $\mathrm{Fe}$ atom at the interface or the same introduced metal atoms substituted in the second layer is less than $0.4 \AA$. In the latter cases, the $\mathrm{Fe}_{3} \mathrm{C}(110)$ configuration at the interface is maintained, keeping a similar structural environment for the carbon atom at the active site.

Figure 3 shows the linear scaling relation of $\Delta G(* \mathrm{OOH})$ vs. $\Delta G(* \mathrm{OH})$ and $\Delta G(* \mathrm{O})$ vs. $\Delta G(* \mathrm{OH})$, excluding the heterostructures with the interface reconstruction and only optimizing the intercept and not the slope of the linear fit. The scaling relations can then be expressed as

$\Delta G(* \mathrm{O})=2 \Delta G(* \mathrm{OH})-0.47 \mathrm{eV}, \mathrm{R}^{2}=0.89, \mathrm{MAE}=0.04 \mathrm{eV}$

$\Delta G(* \mathrm{OOH})=\Delta G(* \mathrm{OH})+3.50 \mathrm{eV}, \mathrm{R}^{2}=0.98, \mathrm{MAE}=0.01 \mathrm{eV}$

The scaling relation between $\Delta G(* \mathrm{OOH})$ and $\Delta G(* \mathrm{OH})$ is found to be close to the previous study for the carboncoated iron and iron carbide system reported by Reda et al. which is $\Delta G(* \mathrm{OOH})=\Delta G(* \mathrm{OH})+3.4^{[24]}$. The slope of 2 of the $\Delta G(* \mathrm{O})$ vs. $\Delta G(* \mathrm{OH})$ curve and the slope of 1 of the $\Delta G(* \mathrm{OOH})$ vs. $\Delta G\left({ }^{*} \mathrm{OH}\right)$ curve relates to the bond order of $* \mathrm{O}, * \mathrm{OOH}$, and $* \mathrm{OH}$ are consistent with those on metal and metal oxide surfaces ${ }^{[4]}$. However, the constant separation of -0.47 belonging to the $\Delta G(* 0)$ vs. $\Delta G(* \mathrm{OH})$ curve and 3.5 belonging to the $\Delta G(* \mathrm{OOH})$ vs. $\Delta G(* \mathrm{OH})$ curve differ from those on the metal and metal oxide surface. This can be attributed to the different surface structures of the $\mathrm{N}$-doped graphene and the metal (metal oxide) surface. It is known that the intercept is affected by surface geometry ${ }^{[60]}$.

The work function of isolated $\mathrm{N}$-doped graphene in this study is found to be $3.61 \mathrm{eV}$ which is lower than that of pristine graphene with a work function of $4.47 \mathrm{eV}$. Among the heterostructures with negligible interface reconstruction, there is a change in the work function of the overlayer $\mathrm{N}$-doped graphene due to the introduced metal atoms at the substrate. The metal-iron carbide substrates generally increase the work function of the overlayer $\mathrm{N}$-doped graphene. The increase in the work function due to the metal iron carbide substrate of the heterostructures with interlayer distance $<2.4 \AA$ are about $0.29 \mathrm{eV}$ on average, compared to the isolated $\mathrm{N}$ doped graphene. (Table S3, Supporting Information).

The correlation between the work function of graphene and the ORR activity has been already reported for many graphene-based catalysts ${ }^{[19,61-62]}$. In this study, for the heterostructure with negligible interface reconstruction and the interlayer distance $<2.4 \AA$, it has been found that the trend of the work function of the overlayer $\mathrm{N}$-doped graphene $\left(W F_{N G}\right)$ follows the trend in the adsorption energies of the ORR (Figure 4).

The correlation between the change in intermediate binding energy and the Bader charge on the intermediate $[17,24]$ as well as the $p_{z}$ band center of carbon atoms on the graphene sheet ${ }^{[63,64]}$ have been proposed for many graphene-based catalysts.

However, our Bader charges analysis does not reveal a clear correlation between the Bader charge and the binding energy of $*^{O} \mathrm{O}$ intermediate. (Figure $\mathrm{S} 1$,
Supporting Information). According to our calculations, the Bader charge of the *O intermediate on different heterostructures vary within a narrow range $(1.18 \pm 0.02$ electron), irrespective of the binding energy of $* 0$. In contrast, previous reports considered systems with variations in $* O$ bader charge of 0.3 electrons. ${ }^{[24]}$

We considered the projected density of states (PDOS) onto the $p_{z}$ orbital of the carbon atom at the active site. The $p_{z}$ band center is calculated relative to the Fermi level. Among the heterostructures with negligible surface reconstruction and interlayer distance $<2.4 \AA$, we found that the $\mathrm{Fe}_{3} \mathrm{C}$ and $\mathrm{M}_{-} \mathrm{Fe}_{3} \mathrm{C}$ substrates shift the $p_{z}$ band center of a carbon atom at the active site of the isolated $\mathrm{N}$-doped graphene to lower energy value (Table S3, Supporting Information). Our results show no correlation between the $p_{z}$ band center of the active carbon atom and the adsorption energy (Figure S2 (a-b), Supporting Information). We further investigate the $p_{z}$ band center of all carbon atoms on the overlayer $\mathrm{N}$-doped graphene, and find that the binding energies of the ORR intermediates are correlated with the $p_{z}$ band center of all carbon atoms on the $\mathrm{N}$-doped graphene (Figure S2(c-d), Supporting Information). The correlation becomes more obvious when the $p$ band center of carbon atoms on the overlayer $\mathrm{N}$-doped graphene, $C(p)_{N G}$, is plotted against the adsorption energy of the ORR intermediates as shown in Figure $4(c-d)$. The binding strength of the ORR intermediates on the overlayer $\mathrm{N}$-doped graphene decrease as the $C(p)_{N G}$ moves toward the Fermi Level. The relation between the deeper valence orbital levels of the graphene sheet with the larger binding strength with the reaction intermediate has been reported and explained in the previous study by Zhou et al. using extended Hückel theory. ${ }^{[63]}$ The interaction between the $\mathrm{N}$-doped graphene surface and the adsorbates seems to be a delocalized interaction. The theoretical study by Chen et al. ${ }^{[65]}$ suggests that the $\mathrm{N}$-dopant atom on the graphene sheet can introduce more delocalized "electrondonating area" on the graphene sheet and activate $\mathrm{sp}^{2}$ of the carbon atoms near the active site to be involved in the bonding with the adsorbate.

Moreover, we considered the PDOS on atoms in the heterostructures (with negligible interface reconstruction and the interlayer distance $<2.4 \AA$ ) before and after the *O intermediate is adsorbed on the heterostructure (Figure S3 and S4, Supporting information). The PDOS onto the $\mathrm{p}$ orbital of the $* O$ adsorbate on all the considered heterostructures are located below the Fermi level (also the PDOS onto the s orbital), suggesting fully occupied $* O(p)$ states. The adsorption of the $* O$ intermediate on the heterostructure causes a shift of $C(p)_{N G}$, whereas there is no apparent change in the metal $\mathrm{d}$ orbitals of the heterostructures due to the *O adsorption.

We also considered the $d$ band center and the work function of the isolated metal-iron carbide substrate as a function of the adsorption energy of the ORR intermediates as shown in Figure S5, Supporting Information. The general trend of binding strength and the work function of the isolated substrate can be seen, especially of the second layer substitution. The binding strength of the ORR intermediates generally increases as 
the work function of the substrate decrease. The lower work function allows electrons from the substrate to be donated easier to the overlayer $\mathrm{N}$-doped graphene and the adsorbates, thereby enhance the binding strength. However, our result did not show a correlation between the $\mathrm{d}$ band center of the substrate and the adsorption strength.

The introduction of metal atoms into the substrate can modify the electronic structure of the overlayer $\mathrm{N}$-doped graphene, evident in the change of the work function and the shift of the $\mathrm{p}$ band center of the overlayer $\mathrm{N}$-doped graphene which is believed to participate in bonding with the adsorbates.

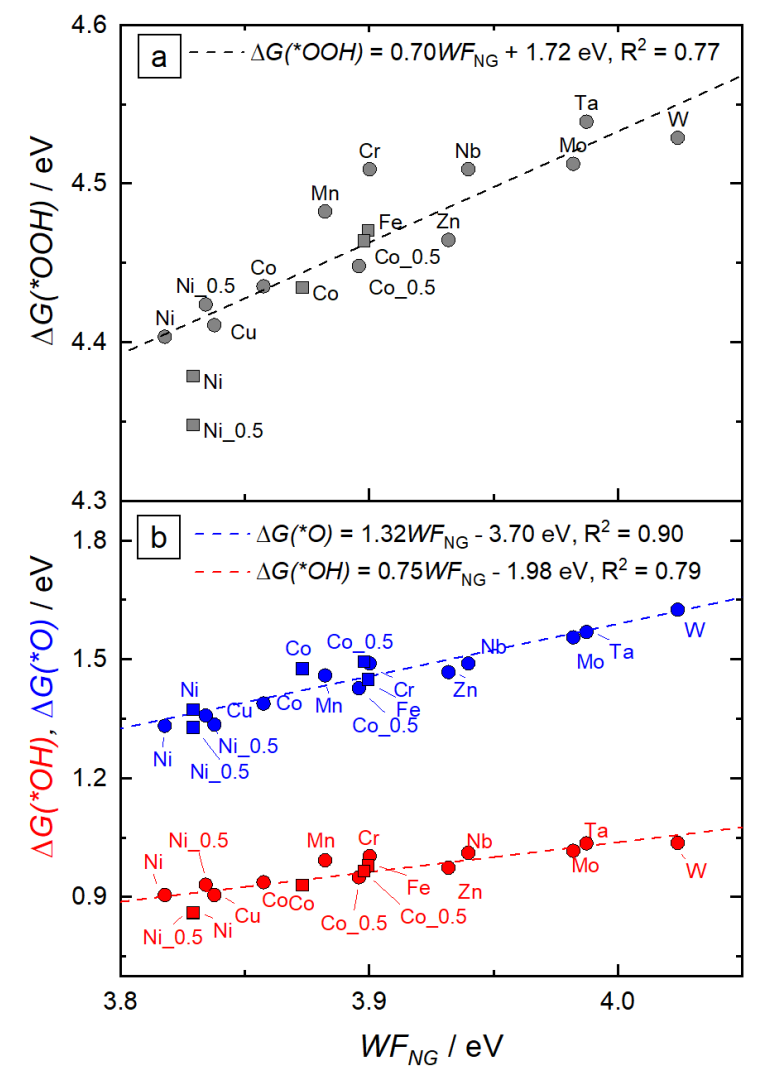

Figure 4. Correlation between the adsorption free energies of the adsorbate on the NG/M_Fe $\mathrm{F}_{3} \mathrm{C}$ with (a-b) the work function of the overlayer $\mathrm{N}$-doped graphene, and $(c-d)$ the $p$ band center of carbon atoms on the overlayer $\mathrm{N}$-doped graphene $\left(C(p)_{\mathrm{NG}}\right) . \Delta G(* \mathrm{O}), \Delta G(* \mathrm{OH})$, and $\Delta G(* \mathrm{OOH})$ are plotted in blue, red, and black color respectively. The squares and circles mark the data from the $1^{\text {st }}$ and $2^{\text {nd }}$ layer substitution, respectively. The plot includes Ni_0.5 and Co_0.5, denoting $\mathrm{Ni}$ and $\mathrm{Co}$ atoms, respectively substitute that only half of $\mathrm{Fe}$ atoms in the layer. The $C(p)_{N G}$ is calculated relative to the Fermi level and the negative value means the $C(p)_{N G}$ locates below the Fermi level.

The ORR overpotential as a function of $\Delta G(* O)$ and $\Delta G(* O H)$ is shown in Figure $5(\mathrm{a}) . \Delta G(* \mathrm{OOH})$ is calculated from the scaling relation in Equation (19) which limits the minimum overpotential of the considered system at 0.52 $\mathrm{V}$. In case of the heterostructures with $\mathrm{Cu}$ and $\mathrm{Zn}$ atoms at the interface where the overlayer $\mathrm{N}$-doped graphene interact weakly with the substrate, the intermediate bind weakly with the carbon atom at the active, resulting in low ORR activity. The most active heterostructure for the ORR is found to be the heterostructure with $\mathrm{Ni}$ atoms at the interface. The overpotential of this heterostructure is found to be $0.72 \mathrm{~V}(0.06 \mathrm{~V}$ lower than that of the $\mathrm{NG} / \mathrm{Fe}_{3} \mathrm{C}$ ). Other heterostructures showing improved ORR activity over $\mathrm{NG} / \mathrm{Fe}_{3} \mathrm{C}$ are the heterostructure with Co atoms at the interface $($ IORR $=0.74 \mathrm{~V})$ and the heterostructure with $\mathrm{Zn}$ at the second layer of $\mathrm{Fe}_{3} \mathrm{C}$ substrate $($ IORR $=0.77 \mathrm{~V})$.

Taking the stability of the heterostructure into account

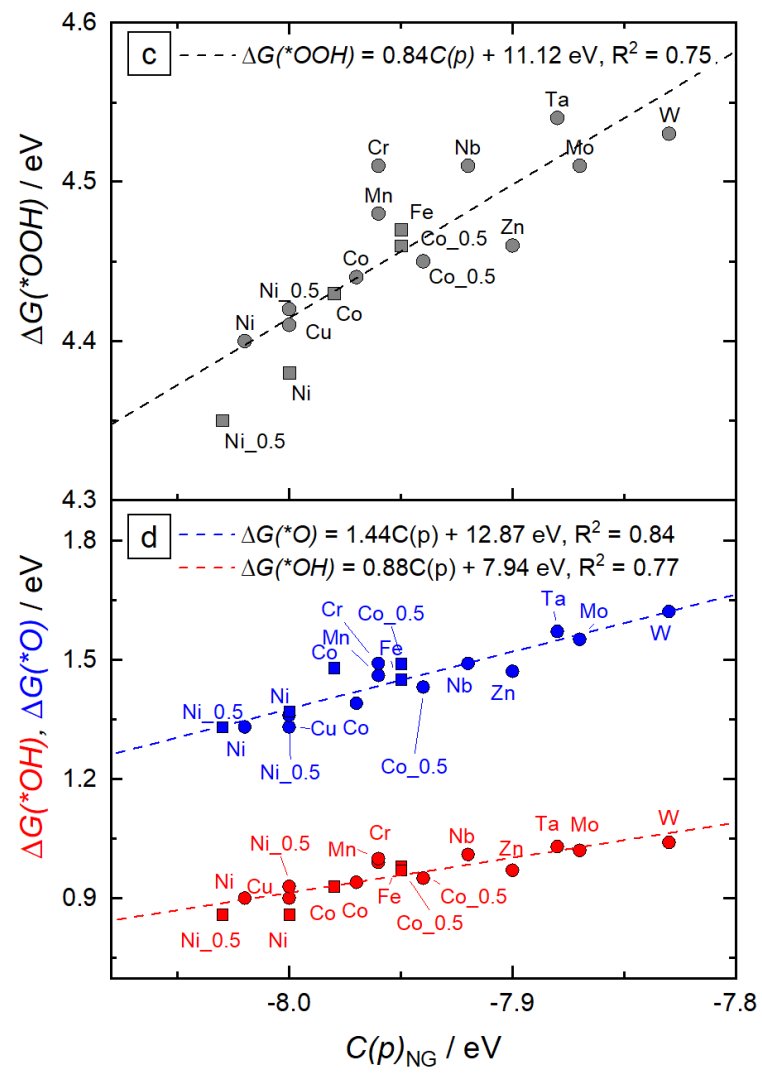

as shown in Figure 5(b), the promising heterostructures located in the green area, which show improved ORR catalytic activity over $\mathrm{NG} / \mathrm{Fe}_{3} \mathrm{C}$ and forms a stable structure, are heterostructures with $\mathrm{Ni}$ and $\mathrm{Co}$ atoms at the interface. Although the heterostructure with $\mathrm{Zn}$ atoms in the second layer of the interface shows improved ORR catalytic activity, the stability calculation suggests that the substituted $\mathrm{Zn}$ atoms are more stable at the interface than in the second layer of the substrate. Hence, this heterostructure will not be studied in the following.

The concentration of $\mathrm{N}$ doping in graphene might affect ORR activity. A study by Kwak et al. ${ }^{[57]}$ showed the increase of nitrogen concentration can stabilize the *O intermediate while the $* \mathrm{OH}$ and $* \mathrm{OOH}$ intermediates remain mostly unaffected, while our own previous study highlighted the importance of $* \mathrm{O}$ coverage relative to $\mathrm{N}$ doping concentration. ${ }^{[55]}$ However, we expect the trend in the ORR activity due to the different introduced metal atoms into the $\mathrm{Fe}_{3} \mathrm{C}$ substrate are largely insensitive to the substrate, as that was previously found by by Noh et 
al. ${ }^{[15]}$ for $\mathrm{N}$-doped carbon encapsulating $\mathrm{Fe}, \mathrm{Co}, \mathrm{Ni}$ and $\mathrm{Cu}$ nanoparticles.

The alloy nanoparticle of CoFe carbide encapsulated in the $\mathrm{N}$-doped graphene sheet has already been experimentally synthesized and showed superior ORR catalytic activity compared to $\mathrm{NG} / \mathrm{Fe}_{3} \mathrm{C}^{[26]}$, consistent with our findings.

By contrast, our results showing a negative effect of the incorporation of $\mathrm{Mn}$ atoms into the $\mathrm{Fe}_{3} \mathrm{C}$ substrate do not agree well with the experiments which have been reported by Lin et al. ${ }^{[27]}$ In our study, substituting $\mathrm{Mn}$ atoms at the first layer of the $\mathrm{Fe}_{3} \mathrm{C}$ substrate results in a higher overpotential than that of the $\mathrm{NG} / \mathrm{Fe}_{3} \mathrm{C}$ heterostructure while the second layer substitution results in a comparative overpotential with only $0.01 \mathrm{~V}$ higher than that of the pristine heterostructure. Note that the substitution of $\mathrm{Mn}$ atoms at the interface causes the interface reconstruction which is believed to affect the adsorption energy of the adsorbates. Besides, the formation energy calculations show that $\mathrm{Mn}$ atoms possibly distribute in both the first and second layer of the $\mathrm{Fe}_{3} \mathrm{C}$ substrate as the formation energy difference between the first- and second-layer substitution is less than $0.01 \mathrm{eV}$. Elucidating the effect of $\mathrm{Mn}$ atoms in the $\mathrm{Fe}_{3} \mathrm{C}$ substrate, more calculations with an increasing number of $\mathrm{Mn}$ atoms in the subsurface layers (i.e. the second and the third layer of the $\mathrm{Fe}_{3} \mathrm{C}$ substrate) or less $\mathrm{Mn}$ atoms in the first layer (to make the interface reconstruction less severe) are required.

The ORR activity obtained from the model when atomic reconstruction at the interface is negligible, such as NG/Co_Fe ${ }_{3} \mathrm{C}$, is in line with the experiment, therefore, our ORR model can give guide design of ORR catalyst in these cases. When the heterostructure interface reconstructs, the model can possibly be improved by reducing the concentration of the introduced metal atoms at the interface to mitigate the interface reconstruction.

Stability and ORR activity as a function of substituted metal concentration. Since the introduction of $\mathrm{Ni}$ and $\mathrm{Co}$ atoms at the $\mathrm{NG} / \mathrm{Fe}_{3} \mathrm{C}$ interface improves ORR activity of the $\mathrm{NG} / \mathrm{Fe}_{3} \mathrm{C}$ structure, the effect of $\mathrm{Ni}$ and $\mathrm{Co}$ concentrations in the $\mathrm{Fe}_{3} \mathrm{C}$ substrate on the ORR catalytic activity as well as the stability of the heterostructure is discussed in the following content. $\mathrm{Ni}$ and $\mathrm{Co}$ atoms substitute $\mathrm{Fe}$ atoms in the $\mathrm{Fe}_{3} \mathrm{C}$ substrate up to three layers from the interface. Further substitution in the fourth layer from the interface has less effect on the ORR catalytic activity (Figure 6(b)). The substituted concentration is defined as the percentage of Fe atoms in the first three layers of the $\mathrm{Fe}_{3} \mathrm{C}$ substrate which are substituted by $\mathrm{Ni}$ or $\mathrm{Co}$ atoms.

We evaluate the stability of heterostructures with different concentration of $\mathrm{Ni}$ and $\mathrm{Co}$ atoms in the $\mathrm{Fe}_{3} \mathrm{C}$ substrate by calculating the formation energy of the heterostructures relative to pure metal and metal carbide phase of $\mathrm{Ni}$ and $\mathrm{Co}$ as defined in Equation (3) because $\mathrm{Ni}$ and $\mathrm{Co}$ are more stable in their metal phases than in their metal carbide phase.
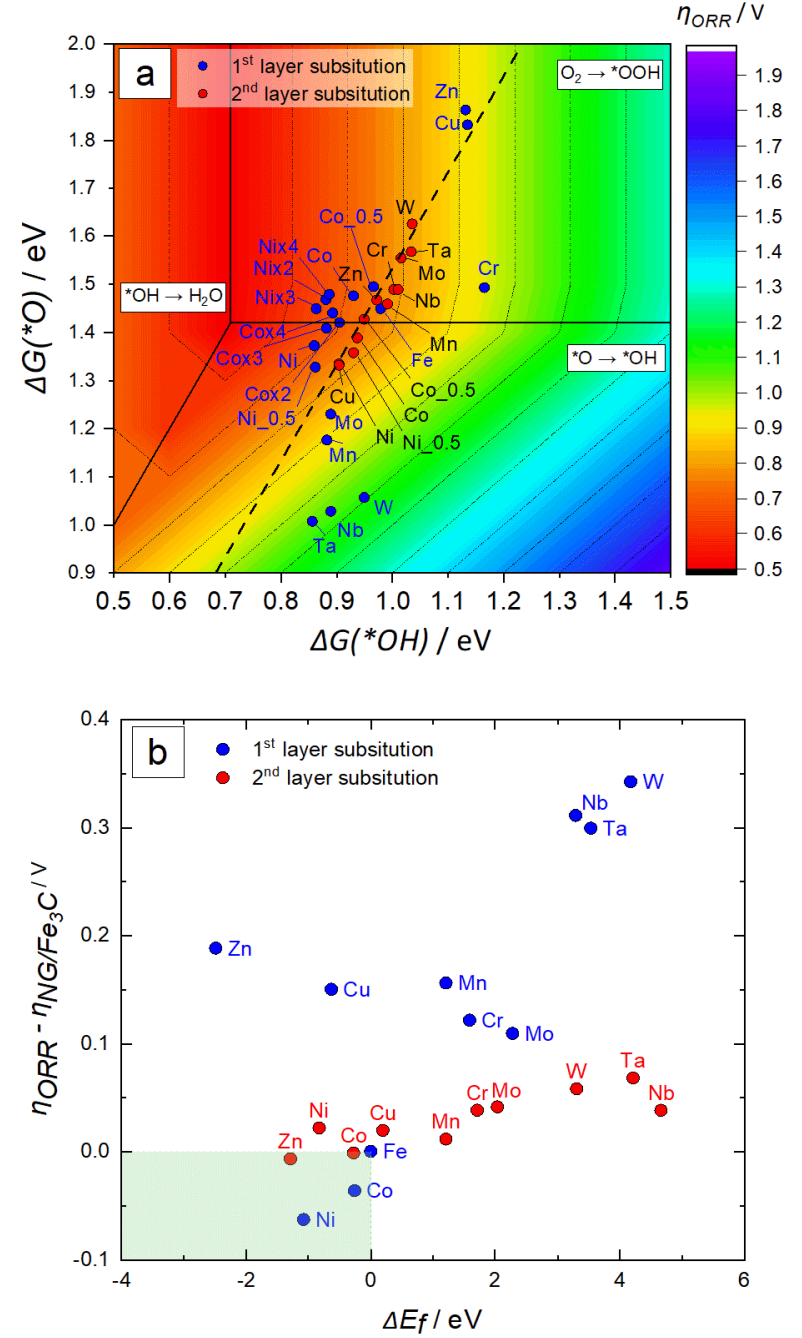

Figure 5 (a) ORR overpotential along the four-electron associative pathway as a function of $\Delta G(* \mathrm{O})$ and $\Delta G(* \mathrm{OH})$. The scaling relation between $\Delta G(* \mathrm{OOH})$ and $\Delta G(* \mathrm{OH})$ in Equation (19) is used. The plot is divided into three areas separated by solid black lines and based on the limiting step, which is shown in the white boxes. The black dash line shows the scaling relation between $\Delta G(* \mathrm{O})$ and $\Delta G(* \mathrm{OH})$ in Equation (18). The plot includes $\mathrm{Ni} 0.5$ and Co_0.5, which denotes that only half of Fe atoms in the layer are substituted while $\mathrm{Ni} x \mathrm{X}$ and $\mathrm{Co} \mathrm{X}$ $X$ (where $X=2,3,4$ ) denote that $X$ Fe layers from the interface are substituted. (b) ORR overpotential on $\mathrm{NG} / \mathrm{M} \_\mathrm{Fe}_{3} \mathrm{C}$ relative to $\mathrm{NG} / \mathrm{Fe}_{3} \mathrm{C}$ vs. formation energy $\left(\Delta E_{f}\right)$.

As shown in Figure 6(a), the formation energies of the heterostructure with $\mathrm{Ni}$ atoms are exothermic for all considered concentrations, and the substituted $\mathrm{Ni}$ atoms preferably locate at the $\mathrm{Fe}_{3} \mathrm{C}$ surface rather than distribute in the substrate. At excessive concentration $(>67 \% \mathrm{Ni}$ ) where $\mathrm{Ni}$ atoms start to substitute in the third layer of the $\mathrm{Fe}_{3} \mathrm{C}$ substrate, the formation energy becomes less negative as the substituted concentration increase. 
In the case of the Co atoms, the substitution is also possible at many concentrations as the calculations show negative formation energy. A similar trend in the formation energy as that with $\mathrm{Ni}$ substitution was observed. The formation energy becomes less exothermic at high concentration (> 33\%Co) and becomes endothermic at the concentration where all Fe atoms in the first three layers are replaced $(100 \% \mathrm{Co})$. However, the distribution of $\mathrm{Co}$ atoms in the $\mathrm{Fe}_{3} \mathrm{C}$ substrate is unlike the case of $\mathrm{Ni}$ atoms. At a certain concentration, in the stable structure, Co atoms are energetically favorable to distribute into the substrate. These results are explained by $\Delta E_{\text {int }}$ and related to the segregation. In an alloy compound, the component with low surface energy tend to segregate to the surface, and the difference in energy required to form the surface between the constituent components will drive the segregation ${ }^{[15,41,43]}$. In the case of $\mathrm{Co}$, we find that $\Delta E_{\text {int }}$ of $\mathrm{Co}$ is lower than that of $\mathrm{Fe}$, which suggests that $C_{0}$ is more likely to form a surface layer than Fe. However, the $\Delta E_{\text {int }}$ difference between Co and $\mathrm{Fe}$ is possibly not large enough to suppress the segregation of Fe atom toward the surface since we also find a negative value of $\Delta E_{\text {exc }}$ (Table S2, Supporting Information). For $\mathrm{Ni}$, we find a lower $\Delta E_{\text {int }}$ than that of $\mathrm{Fe}$ and larger a $\Delta E_{\text {int }}$ difference than in the case of Co. Therefore, the segregation of $\mathrm{Ni}$ dominates, making $\mathrm{Ni}$ likely to enrich the $\mathrm{Fe}_{3} \mathrm{C}$ surface (Table S2, Supporting Information).

The ORR overpotential is calculated as a function of $\mathrm{Ni}$ and $\mathrm{Co}$ concentration in the $\mathrm{Fe}_{3} \mathrm{C}$ substrate. We find that at a specific concentration, the most stable structure is also the most active structure for the ORR. In general, increasing the number of $\mathrm{Ni}$ or $\mathrm{Co}$ atoms in the $\mathrm{Fe}_{3} \mathrm{C}$ substrate near the interface increases the stabilization of the ORR intermediates on the overlayer $\mathrm{N}$-doped graphene and enhances the ORR catalytic activity of the heterostructure. However, at some concentrations, there is more than one thermally accessible structure, i.e. configuration $\mathrm{B}$ and $\mathrm{C}$ at $17 \% \mathrm{Ni}$, since the difference in $\Delta E_{f}$ of the configurations is less than $25 \mathrm{meV} /$ (substituted atom).

The lowest overpotentials are found to be 0.70 and $0.72 \mathrm{~V}$ at a surface concentration of $67 \% \mathrm{Ni}$ and more than $100 \%$ Co, respectively. The lowest overpotentials with Ni substitution is possible on stable heterostructures. However, for Co substitution, the heterostructure with the lowest overpotential is predicted to be unstable, so the lowest overpotential might be slightly higher than predicted.

It is important to note that the distribution of the substituted atoms near the interface significantly affects the ORR activity on the overlayer $\mathrm{N}$-doped graphene. At the same concentration, the heterostructure with more $\mathrm{Ni}$ or $\mathrm{Co}$ atoms at the interface (in the first layer of the $\mathrm{Fe}_{3} \mathrm{C}$ substrate) results in the lower ORR overpotential. On the other hand, interface rearrangement or reconstruction increases with the concentration of $\mathrm{Ni}$ or $\mathrm{Co}$ at the interface. As previously discussed, the interface reconstruction causes the adsorption energies to deviate slightly from the linear scaling relations, especially for $\Delta G(* \mathrm{O})$ vs $\Delta G(* \mathrm{OH})$ with $\mathrm{Ni}$ and Co substitution (Figure S7, Supporting Information). However, in these cases, the deviation from the scaling relation (Equation (18)) occurs in a way which is likely to improve the ORR activity.

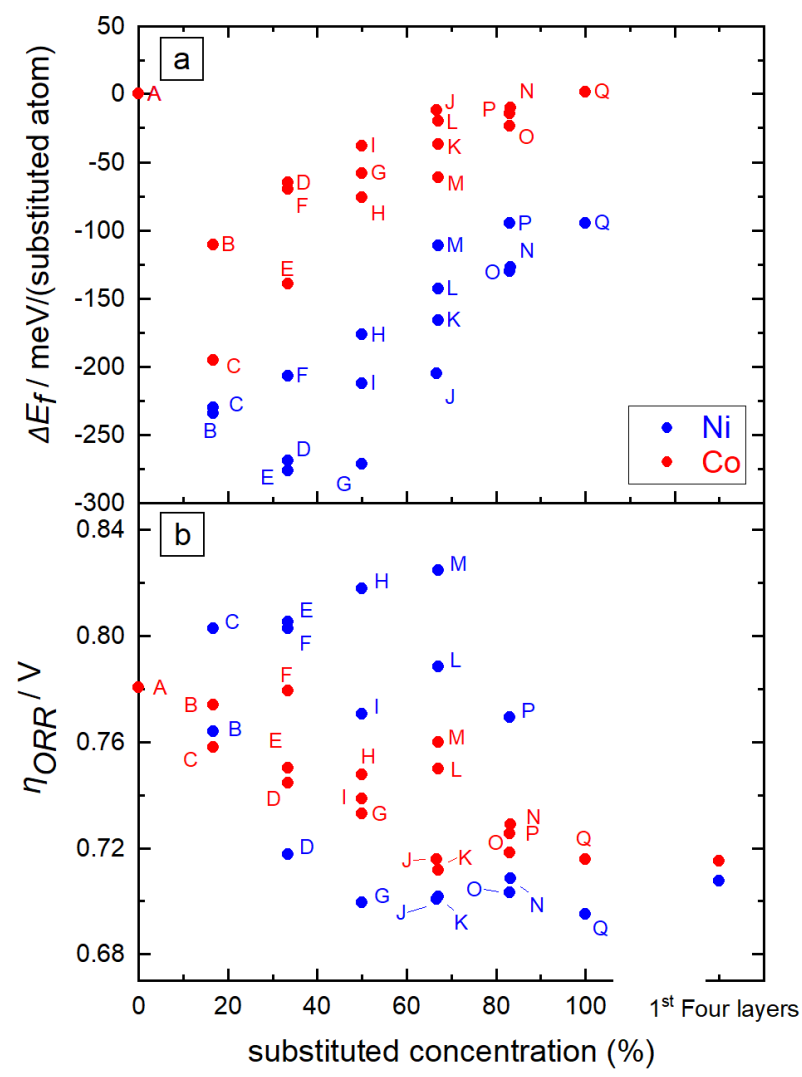

Figure 6. (a) Formation energy in $\mathrm{meV} /$ (substituted atom) and (b) ORR overpotential at the different substituted concentrations of $\mathrm{Ni}$ and $\mathrm{Co}$ atoms in the $\mathrm{Fe}_{3} \mathrm{C}$ substrate. The marks with letters $(A)-(Q)$ refer to the different configurations in Figure S6, Supporting Information.

\section{Conclusions}

To summarize, the investigated stability and catalytic activity of the NG/M_Fe 3 C heterostructure where $\mathrm{M}=\mathrm{Cr}$ - Mn, Co - Zn, Nb - Mo, Ta - W toward the ORR are carried out by using DFT calculations. The NG/M_Fe ${ }_{3} \mathrm{C}$ heterostructure is modelled from the $\mathrm{NG} / \mathrm{Fe}_{3} \mathrm{C}$ heterostructure by substituting $\mathrm{Fe}$ atoms in the $\mathrm{Fe}_{3} \mathrm{C}$ substrate near the $\mathrm{NG} / \mathrm{Fe}_{3} \mathrm{C}$ interface with the metal atoms $M$. The introduction of the new metal atoms $M$ near the interface alters the work function of the overlayer $\mathrm{N}$ doped graphene which is found to correlate with the adsorption strength of the ORR intermediates at the active site. The promising candidates which show improved ORR catalytic activity relative to the $\mathrm{NG} / \mathrm{Fe}_{3} \mathrm{C}$ and are able to form stable heterostructures contain $\mathrm{Ni}$ or Co atoms. The stable heterostructures are also available at various substituted concentrations of $\mathrm{Ni}$ and $\mathrm{Co}$, and the ORR activity depends on the substituted concentration. The increasing concentration of $\mathrm{Ni}$ and $\mathrm{Co}$ atoms can further tune the binding energies of the ORR intermediate at the active site, reducing the overpotential. We hence propose that incorporating $\mathrm{Ni}$ or Co atoms in 
the $\mathrm{Fe}_{3} \mathrm{C}$ substrate is feasible and could enhance the ORR activity of the $\mathrm{NG} / \mathrm{Fe}_{3} \mathrm{C}$ interface.

\section{Acknowledgments}

This work was supported by the Velux Foundations through the research center V-Sustain (grant no 9455).

Keywords: density functional theory • iron carbide • nitrogen-doped graphene $\bullet$ non-precious metal catalyst - oxygen reduction reaction.

\section{References}

[1] Y. Wang, K. S. Chen, J. Mishler, S. C. Cho, X. C. Adroher, Appl. Energy 2011.

[2] S. O. Mert, I. Dincer, Z. Ozcelik, Int. J. Hydrogen Energy 2012, 37, 623633.

[3] S. J. Peighambardoust, S. Rowshanzamir, M. Amjadi, in Int. J. Hydrogen Energy, Pergamon, 2010, pp. 9349-9384.

[4] D. Banham, S. Ye, ACS Energy Lett. 2017, 626-638.

[5] J. K. Nørskov, J. Rossmeisl, A. Logadottir, L. Lindqvist, J. R. Kitchin, T. Bligaard, H. Jónsson, J. Phys. Chem. B 2004, 108, 17886-17892.

[6] D. Kaewsai, M. Hunsom, Nanomaterials 2018, 8, 299.

[7] R. Ma, G. Lin, Y. Zhou, Q. Liu, T. Zhang, G. Shan, M. Yang, J. Wang, npj Comput. Mater. 2019,78, 1-15

[8] G. Wu, K. L. More, C. M. Johnston, P. Zelenay, Science. 2011, 332, 443447

[9] S. Gupta, D. Tryk, I. Bae, W. Aldred, E. Yeager, J. Appl. Electrochem. 1989, 19, 19-27.

[10] H. T. Chung, D. A. Cullen, D. Higgins, B. T. Sneed, E. F. Holby, K. L. More, P. Zelenay, Science. 2017, 357, 479 LP - 484.

[11] A. Zitolo, V. Goellner, V. Armel, M.-T. Sougrati, T. Mineva, L. Stievano, E. Fonda, F. Jaouen, Nat. Mater. 2015, 14, 937.

[12] M. Lefèvre, E. Proietti, F. Jaouen, J.-P. Dodelet, Science. 2009, 324, 71 LP - 74.

[13] J. A. Varnell, E. C. M. Tse, C. E. Schulz, T. T. Fister, R. T. Haasch, J. Timoshenko, A. I. Frenkel, A. A. Gewirth, Nat. Commun. 2016, 7, 1-9.

[14] Y. Liu, H. Jiang, Y. Zhu, X. Yang, C. Li, J. Mater. Chem. A 2016, 4, 16941701.

[15] S. H. Noh, M. H. Seo, J. Kang, T. Okajima, B. Han, T. Ohsaka, Npg Asia Mater. 2016, 8, e312.

[16] S. H. Noh, M. H. Seo, X. Ye, Y. Makinose, T. Okajima, N. Matsushita, B. Han, T. Ohsaka, J. Mater. Chem. A 2015, 3, 22031-22034.

[17] S. H. Noh, D. H. Kwak, M. H. Seo, T. Ohsaka, B. Han, Electrochim. Acta 2014, 140, 225-231.

[18] Y. Hu, J. O. Jensen, W. Zhang, L. N. Cleemann, W. Xing, N. J. Bjerrum, Q. $\mathrm{Li}$, Angew. Chemie - Int. Ed. 2014, 53, 3675-3679.

[19] D. Deng, L. Yu, X. Chen, G. Wang, L. Jin, X. Pan, J. Deng, G. Sun, X. Bao, Angew. Chemie - Int. Ed. 2013, 52, 371-375.

[20] J. Wang, H. Wu, D. Gao, S. Miao, G. Wang, X. Bao, Nano Energy 2015, $13,387-396$.

[21] L. Zhong, Y. Hu, L. N. Cleemann, C. Pan, J. Sværke, J. O. Jensen, Q. Li, Int. J. Hydrogen Energy 2017, 42, 22887-22896.

[22] Y. Hu, J. O. Jensen, W. Zhang, S. Martin, R. Chenitz, C. Pan, W. Xing, N. J. Bjerrum, Q. Li, J. Mater. Chem. A 2015, 3, 1752-1760.

[23] L. Zhong, C. Frandsen, S. Mørup, Y. Hu, C. Pan, L. N. Cleemann, J. O. Jensen, Q. Li, Appl. Catal. B Environ. 2018, 221, 406-412.

[24] M. Reda, H. A. Hansen, T. Vegge, ACS Catal. 2018, 8, 10521-10529.

[25] J. Gautam, T. D. Thanh, K. Maiti, N. H. Kim, J. H. Lee, Carbon N. Y. 2018, 137, 358-367.
[26] C. Lin, X. Li, S. S. Shinde, D. H. Kim, X. Song, H. Zhang, J. H. Lee, ACS Appl. Energy Mater. 2019, 2, 1747-1755.

[27] J. Mao, Y. Wang, Z. Zheng, D. Deng, Front. Phys. 2018, 13(4), 138118.

[28] G. Kresse, J. Hafner, Phys. Rev. B 1995, 92-193,222-229.

[29] G. Kresse, J. Hafner, Phys. Rev. B 1994, 49, 14251-14269.

[30] G. Kresse, J. Furthmüller, Phys. Rev. B - Condens. Matter Mater. Phys. 1996, 54, 11169-11186.

[31] G. Kresse, J. Furthmüller, Comput. Mater. Sci. 1996, 6, 15-50.

[32] A. Hjorth Larsen, J. Jørgen Mortensen, J. Blomqvist, I. E. Castelli, R. Christensen, M. Dułak, J. Friis, M. N. Groves, B. Hammer, C. Hargus, et al., J. Phys. Condens. Matter 2017.

[33] P. E. Blöchl, Phys. Rev. B 1994, 50, 17953-17979.

[34] D. Joubert, Phys. Rev. B - Condens. Matter Mater. Phys. 1999, 59, 17581775.

[35] J. Wellendorff, K. T. Lundgaard, A. Møgelhøj, V. Petzold, D. D. Landis, J. K. Nørskov, T. Bligaard, K. W. Jacobsen, Phys. Rev. B - Condens. Matter Mater. Phys. 2012, 85.

[36] K. Lee, É. D. Murray, L. Kong, B. I. Lundqvist, D. C. Langreth, Phys. Rev. $B$ - Condens. Matter Mater. Phys. 2010, 82.

[37] J. Wellendorff, T. L. Silbaugh, D. Garcia-Pintos, J. K. Nørskov, T. Bligaard F. Studt, C. T. Campbell, Surf. Sci. 2015, 640, 36-44.

[38] H. J. Monkhorst, J. D. Pack, Phys. Rev. B 1976, 13, 188-5192.

[39] S. Seraphin, J. Electrochem. Soc. 1995, 142, 290-297.

[40] S. Seraphin, D. Zhou, J. Jiao, J. Appl. Phys. 1996, 80, 2097-2104.

[41] A. V. Ruban, H. L. Skriver, J. K. Nørskov, Phys. Rev. B - Condens. Matter Mater. Phys. 1999, 59, 15990-16000.

[42] Y. Yu, W. Xiao, J. Wang, L. Wang, Phys. Chem. Chem. Phys. 2016, 18, 26616-26622.

[43] P. A. Dowben, A. H. Miller, R. W. Vook, Gold Bull. 1987, 20, 54-65.

[44] W. Lee, J. W. Han, Y. Chen, Z. Cai, B. Yildiz, J. Am. Chem. Soc. 2013, $135,7909-7925$

[45] D. Guedes-Sobrinho, R. K. Nomiyama, A. S. Chaves, M. J. Piotrowski, J. L. F. Da Silva, J. Phys. Chem. C. 2015, 119, 15669-15679.

[46] A. Kulkarni, S. Siahrostami, A. Patel, J. K. Nørskov, Chem. Rev. 2018.

[47] L. Yu, X. Pan, X. Cao, P. Hu, X. Bao, J. Catal. 2011, 282, 183-190.

[48] H. J. Yan, B. Xu, S. Q. Shi, C. Y. Ouyang, J. Appl. Phys. 2012, 112.

[49] F. Studt, Catal. Letters 2013, 143, 58-60.

[50] R. C. Weast, CRC Handbook of Chemistry and Physics: A Ready-Reference Book of Chemical and Physical Data, 1986.

[51] N. I. of S. and Technology, NIST Comput. Chem. Comp. Benchmark Database 2011.

[52] R. Christensen, H. A. Hansen, T. Vegge, Catal. Sci. Technol. 2015, 5 4946-4949.

[53] R. Christensen, H. A. Hansen, C. F. Dickens, J. K. Nørskov, T. Vegge, J. Phys. Chem. C. 2016, 120, 24910-24916.

[54] J. Rossmeisl, A. Logadottir, J. K. Nørskov, Chem. Phys. 2005, 319, 178184.

[55] M. Reda, H. A. Hansen, T. Vegge, Catal. Today 2018, 312, 118-125.

[56] S. P. Walch, J. Phys. Chem. C 2011, 115, 7377-7391.

[57] D. Kwak, A. Khetan, S. Noh, H. Pitsch, B. Han, ChemCatChem 2014, 6, 2662-2670.

[58] S. Goedecker, W. Hellmann, T. Lenosky, Phys. Rev. Lett. 2005, 95

[59] S. Goedecker, J. Chem. Phys. 2004, 120, 9911-9917.

[60] V. Viswanathan, H. A. Hansen, J. Rossmeisl, J. K. Nørskov, ACS Catal. 2012, 2, 1654-1660.

[61] M. Sharma, J. H. Jang, D. Y. Shin, J. A. Kwon, D. H. Lim, D. Choi, H. Sung, J. Jang, S. Y. Lee, K. Y. Lee, et al., Energy Environ. Sci. 2019, 12, 2200-2211.

[62] J. Y. Cheon, J. H. Kim, J. H. Kim, K. C. Goddeti, J. Y. Park, S. H. Joo, J. Am. Chem. Soc. 2014, 136, 8875-8878.

[63] S. Zhou, X. Yang, W. Pei, N. Liu, J. Zhao, Nanoscale 2018, 10, 1087610883.

[64] S. Zhou, N. Liu, Z. Wang, J. Zhao, ACS Appl. Mater. Interfaces 2017, 9, 22578-22587.

[65] J. F. Chen, Y. Mao, H. F. Wang, P. Hu, ACS Catal. 2016, 6(10), 68046813.

.




\section{WILEY-VCH}

\section{FULL PAPER}

\section{Entry for the Table of Contents}

\section{Layout 1:}

\section{FULL PAPER}

The $\mathrm{N}$-doped graphene
supported on $\mathrm{Fe}_{3} \mathrm{C}(010)$ has
been recognized as an active
ORR catalyst. The improved
catalytic activity toward and
stability of the $\mathrm{N}$-doped
graphene supported on
$\mathrm{Fe}_{3} \mathrm{C}(010)$ is achieved by
incorporating Ni or Co atoms in
the Fe ${ }_{3} \mathrm{C}$ supported layer.

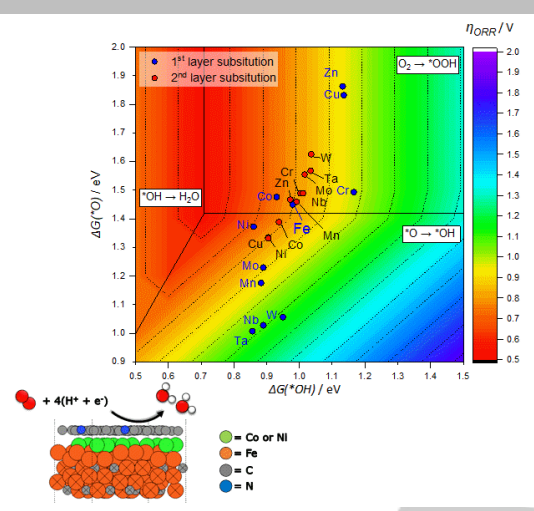

Tipaporn Patniboon, Heine Anton Hansen*

Page No. - Page No.

$\mathbf{N}$-doped graphene supported on metal-iron carbide as a catalyst for oxygen reduction reaction: a density functional theory study 